\title{
A Pragmatic Analysis of Flirtations and Their Functions in Characterization in Gone with the Wind: A Case Study of Scarlett
}

\author{
Xiaoqin $\mathrm{Wu}^{1}$ \\ ${ }^{1}$ Southwest University, China \\ Correspondence: Xiaoqin Wu, Southwest University, Beibei District, Chongqing Municipality, China. E-mail: \\ 903639829@qq.com
}

Received: September 17, 2016 Accepted: October 10, 2016 Online Published: November 29, 2016

doi:10.5539/ells.v6n4p44 URL: http://dx.doi.org/10.5539/ells.v6n4p44

\begin{abstract}
Scarlett O'Hara in Gone with the Wind has left a deep impression for her coping attitude towards romance, marriage and business. It is interesting that these three aspects of her life are more or less related to her flirtations with men. The characteristic language in those flirtations makes a perfect material for her personality analysis. In this paper, the flirtations by Scarlett in Gone with the Wind is analyzed in the framework of the conversational implicature and relevance theory with an aim to demonstrate how such violations of cooperative principle function in the characterization of the protagonist as well as the development of plot and theme. Ultimately this paper is to illustrate how such pragmatic analysis may contribute to literary criticism. Flirtation is the explicit violation of cooperative principle under which a traditionally successful communication is yielded. However, a large number of successful communications have also been found although they violate this principle, especially in literary works. Such violations are ideal materials to study the personalities of communicators. Through a detailed analysis of four classic violations of maxims, Scarlett's personality in Gone with the Wind is scrutinized, social causes of such personality are explained and the novelist's intention to promote women consciousness and independence is discovered.
\end{abstract}

Keywords: Gone with the Wind, flirtations, conversational implicature, characterization, development of plot and theme

\section{Introduction}

Gone with the Wind has been the constant subject of academic researches, the personality research in particular. This book has provided a dozen of impressive and unforgettable characters, among which Scarlett is the most shining and memorable one. So far, great academic attention has been attached to her. After a detailed reading, we find out Scarlett tends to express her intention implicitly and mostly in the form of flirtation. Surprisingly, Scarlett usually manages to be perfectly understood and this violation of cooperative principle secures the success of a communication. This is apparently inconsistent with traditional idea that communication only works effectively when communicators cooperate with each other. This research analyzes Scarlett's flirtations and discovers that the author of this novel designs thusly in a deliberate way, since pragmatic intention is realized via the violation of cooperative principle and strong personality traits are portrayed accordingly. Furthermore, through this pragmatic analysis we revel that marriage bonded by money can hardly create happiness but misery. Consequently the following conclusion can be drawn: it is a desirable strategy to apply conversational implicature to literary works given its effects on the shaping of characteristics, the exposure of social reality and the rendering of conversational motivation (Zhang, 2009, p. 28). However, to date, few scholars have tried to conduct a thorough research on flirtations in Gone with the Wind.

In this paper, the flirtation by Scarlett in Gone with the Wind is analyzed in the framework of the conversational implicature and relevance theory with an aim to show how such violations of cooperative principle function in the characterization of the protagonist as well as in the development of plot and theme in the novel. Ultimately this paper is to illustrate how pragmatic analysis may contribute to literary criticism.

This paper consists of five parts. The first part is the reference to the previous research on flirtations, conversational implicatures and characterization in Gone with the Wind. The second part is theoretical preparation, where the research suggests the conversational implicature and relevance theory can be applied to literary criticism. The third part is the pragmatic analysis of four violations of maxims from the perspective of 
conversational implicature and relevance theory. The fourth part focuses on the literary function of Scarlett's flirtation in characterization and development of plot and theme. The last part is conclusion, consisting of a brief summary of the major findings of this thesis, followed by some prospects for future research in relevant areas.

\section{Literature Review}

\subsection{Previous Studies on Conversational Implicature}

Previous studies on conversational implicature can be divided into Grecian study and Post- Grecian study. There is no exaggeration that Grice's theory of conversation functions as the vein of pragmatics, the theory of conversational implicature in particular. Pragmatists generally recognize Grice's contribution to this field for his formalized account of the distinction between what is said and what is implicated-implicature. Hereafter it has been an important terminology of present day pragmatics as well as a commonly shared interest of pragmatic study, which mainly focuses on the boundary between literal meaning and implicature and on the viability of compartmentalization. However dispute emerges concerning the viability of an autonomous level of "what is said", especially the fact that the linguistic content of an utterance is unable to produce a distinguishable propositional meaning (Siobhan, 2013, p. 157). Investigations are also carried out on the definition of implicature and its relation to speaker's intention, communicative responsibility and normativity. This leads to the conclusion that inference should not be regarded as conversational implicature, which arises retort from Claudia who holds the opposite views.

It is a shared knowledge that communication fails to proceed without cooperation between speaker and hearer. Hence Grice together with other pragmatists realizes its defect and develops cooperative principle (Philip, 1979). As a violation of cooperation principle, conversational analysis rests on the basic assumption that "the act of conversation is not simply developed spontaneously but rather it follows a set of rules, which is different in different culture and contexts" (Goodwin \& Heritage, 2006). Similarly, a model is presented and in this model implicature stands reasonable in a strongly non-cooperative setting and "The model makes clear on a hidden reputation effect that is constant in extended conversation. The foundation of this model rests on ideas from politeness theory, regimented within the framework of game theory." (Nicholas, 2014, p. 20)

Pragmatists after Grice have also made great improvements in the theory of conversational implicature. Wayne A. Davis believes various interpretations are not caused by lexical ambiguity nor their grammatical structure. Mandy (2013, p. 330) concentrates on the question of whether presuppositions are conventional properties of linguistic expressions and argues that "at least some presuppositions should be analyzed as conversational inferences, on the ground that they show two of the hallmarks of such inferences: contextual defeasibility and non-detachability". Philippe (2012, p. 403) Proposes "Maximize Presupposition, which requires that one choose from a predetermined set of competitors and the logical form that marks the strongest presupposition compatible with what is assumed in the conversation". Scott Soames (2008, p. 445) holds the view that restrictions inflicted upon the use of sentences and the information conveyed originates from their conventional meanings as well as the communicative uses.

\subsection{Previous Studies on Flirtation}

Flirtation, as one of the most common human behaviors, has been the research subject in many fields, including social influence, marketing, psychology and so forth. Corruption is revealed by flirtation between civil servants and his mistress through Micro blog and anticorruption battle is launched via internet supervision (Tang, 2011, p. 4); marketing inspiration has been drawn because of flirtation (Jiang, 2014, p. 2); comparative study is carried out on the psychological mechanism between man and woman who are engaged in flirtation and they find out that woman tends to enjoy flirtation since she feels valued and flattered whereas man finds it a toil for the limbic area of his brain is operating and usually lost control when he flirts as he is going through brain damage (Xiao, 2013, p. 8). However, even though flirtation is often seen as a typical example of conversational implicature, we rarely find combined study of flirtation and the theory of conversational implicature, so this paper intends to fill this gap.

\subsection{Previous Studies on Characterization in Gone with the Wind}

Before this study, many personality analyses have been performed in Gone with the Wind, Scarlet in particular. Some deem her a rebellious new woman who dared to challenge the traditional ideology with her non-lady like thoughts and masculine boldness in business and they believe she has gone beyond the contemporary stereotypes of meek and grieving womanhood to the true nature of woman. Her rebel against the fixed position of woman on marriage was regarded as the pursuit of human rights and the reflection of self-consciousness (Ma, 2014, p. 8); Some think of her as a woman of complexity: she is a traditional southern woman and a rebellious southern 
woman; she is a war-battling woman and a woman in pursuit of true love; she is an economically dependent woman and a woman starting her own business against all odds ( $\mathrm{Li}, 2014$, p. 32). There is no doubt that divergence indeed exists when evaluating Scarlett. However, few would argue that Scarlett is a new woman in its true sense and therefore suitable to academic research.

\subsection{Summary}

All in all, in the area of pragmatics, little effort has been invested to study flirtation although it is a classic example of conversational implicature and it helps build up the character's image and promote the development of theme. However its research value will be manifested once it is analyzed from the perspective of conversational implicature and relevance theory.

\section{Theoretical Framework}

\subsection{The Classical Theory of Implicature}

\subsubsection{The Cooperative Principle}

In daily life conversation, people do not usually say things directly but tend to imply them. This engenders ambiguity upon the hearer. However there is some regularity in conversation. "Our talk exchanges do not normally consist of a succession of disconnected remarks and would not be rational if they did. They are characteristically, to some degree at least, cooperative efforts and each participants recognizes in them, to some extent, a common purpose or set of purpose or at least a mutually accepted directions", in other words, we seem to follow the following principles: "make your conversational contribution such as is required, at the stage at which it occurs, by the accepted purpose or direction of the talk exchange in which you are engaged" (Grice, 1975, p. 45). Grice notices these linguistic phenomena and defines it as cooperative principles.

\subsubsection{Violation of the Maxims}

To further specify the cooperative principle, Grice introduces four categories of maxims as follows: quantity - make your contribution as informative as required; quality - make your contribution that is true; relation — be relevant; manner - be perspicuous. He claims when we speak we generally have something like the cooperative principle and its maxims in our mind to guide us, subconsciously or even unconsciously. He revises the misunderstanding that these maxims and principles are prescriptive and speakers are supposed to behave accordingly. In fact, the use of terms "principle" and "maxim" does not mean that the cooperative principle and its maxims will be followed by everybody at any time, so violations indeed exist. Sometimes the quantity maxim will be in conflict with the quality maxim. Though some maxims are violated, the cooperative principle can still be upheld at a deeper level.

\subsubsection{Chracteristics of Implicature}

Toward the end of his "Logic and Conversation", Grice mentioned briefly some characteristics of conversational implicature. He summerized them as calculablity, cancellability (defeasibility), non-detachablity and non-conventionality: Conversational implicatures can be worked out if previous information is provided; if any of the information mentioned earlier changes, the implicature will also change; a conversation implicature is attached to the semantic content of what is said, not to the liguistic form, in other words, an implicature will not be detached from the utterance as a whole, even though the specific words may be changed; implicature is inderterminate, which varies with the context in contrast with entailement.

\subsection{Conversational Implicature and Flirtation}

Flirtation is a social and sexual activity involving verbal or written communication as well as body language by one person to another, suggesting an interest in a deeper relationship with the other person. In most cultures, it is socially disapproved for a person to make explicitly sexual advances, but indirect or suggestive advances are tacitly approved. For that reason, communicators tend to carry their flirtations explicitly and implicature is yielded in this way.

\subsection{Relevance Theory}

\section{Definition of Relevance Theory}

The theory of conversational implicature has offered new explanations for language use. Unfortunately, there is some inconsistency and redundancy among the cooperative principle and its maxims. Therefore, linguists of the post-Grecian period have sought to deformalize the maxims to a set of principles which are truly indispensable and not overlapping at the same time. One of the propositions is relevance theory defined as follows: A remark $P$ is relevant to another remark $\mathrm{Q}$ if $\mathrm{P}$ and $\mathrm{Q}$, together with background knowledge, yield new information not 
derivable from either P or Q, together with background knowledge alone. (ibid.) later Dan Sperber and Deirdre Wilson reduce it as the following: every act of ostensive communication communicates the presumption of its own optimal relevance (1986, p. 158). To understand this definition, we need to be clear about the key notions in it: ostensive communication - makes clear one's intention to express something; presumption of optimal relevance-achieves the biggest communicative effects with the smallest processing efforts.

\subsection{Pragmatic Analysis of Flirtations in the Theory of Implicature and Relevance Theory}

\subsubsection{Violation of Quantity}

Followed by the Quantity Maxim, speakers are supposed to make their own words minute enough but not overloaded to achieve the required communicative effects, in other words, say no more than what is required. Obviously flirtations do not quite meet the requirements.

In this novel Scarlett discusses investment plans with Rhett and complains of her second husband's incompetence. She intends to open her own shop but is short of money so she turns to Rhett. Rhett is very surprised and responds as follows:

"Well. What of it? Haven't you had enough to eat on until he does collect"

"Yes, but well as a matter of fact, I could use a little money right now," her eyes brightened as she thought of the mill, "perhaps."

"What's it for? More taxes?"

"Is that any of your business", "I don't know quite how much 1 will need, "she said sulkily. "but I want to buy a saw mill and I think I can get it cheap. And I will need two wagons and two mules, I want good mules too and a horse and buggy for my own use."

"A saw mill."

When this dialogue begins, Scarlett mentiones roughly her wish to start her own business but lacks money. However, the touch of her hand on Rhett was an extra information which violates the Quantity Maxim. Rhett is shocked but interested enough to hear out her plans. we can see that although she is a woman, she has extraordinary courage and intelligence after a brutal war. Scarlett has a clear understanding of life and she shows a sensible attitude towards the reality of life. A new social system has not been established and the fate of the weak individual is unpredictable, so she has to change herself to adapt to this upcoming new world. In order to support her family and maintain the estate Tara in the cruel world, she becomes more and more attached to money. This reflects that war casts a cruel influence on people and revels the author's intention to promote peace and harmony.

\subsubsection{Violation of Quality}

In accordance with cooperative principle and relevance theory, speakers are supposed to make true statement and avoid what lacks suffficent evidence beause violation of this maxim will increase the processing effort. Some retoric devices such as irony and mataphor in literary works are examples of such violation. However by means of implicit wording, they emphasize the intonation and explain the speakers' intention in a more vivid way. Such examples are numunerous in Gone with the Wind, for instance:

"Why Charles Hamilton, you handsome old thing. I'll bet you came all the way down here from Atlanta just to break my poor heart. Now, you wait right here till I come back, for I want to eat barbecue with you. And don't you go off philandering with those other girls, because I'm mighty jealous."

“I won't. If I went-would-would you be sorry, Miss O’Hara?"

"I should cry into my pillow every night."

"Would you pray for me?"

"Oh- yes indeed, Mr. Hamilton. Three Rosaries a night, at least."

"Will you wait for me, Miss Scarlett? It- it would be heaven just knowing you are waiting for me until after we licked them."

"I wouldn't want to wait."

This conversation occurrs when Scarlett is rejected by the love of her life Ashley and is satirized by his sister behind her back. This act provokes her anger and desire for retribution. Therefore, she seeks Hamilton out and flirts him into proposing, even though she never gives a care about Hamilton and loves no one but Ashley. All she wants is to hurt them back. Obviously she does not tell the truth, which demonstrates her vanity, 
implusiveness and vindictiveness. This implusive act of Scarlett not only foresees the misfortune of her marriage but also produces conflicts among characters and promotes the development of plot.

\subsubsection{Violation of Relevance}

Relevance Maxim requires speaker to express his intention in a corelative and coherent way so the conversation can be carried on or it will reach an impasse. Sometimes delibrate violation of relevance takes place but the hearer could still figure out the conversational implicature based on contexts. It is this indirect experssions that reflect the speaker's mental state more vividly. Filrtations are advanced roundaboutly since social etiquettes disprove explcit sexual advances. Examples can be found in Gone with the Wind as follows:

"Would you mind if I put my hand in your coat pocket. It's so clod and my muff is soaked through."

"Why-why-of course not. And you haven't any gloves. My, my, what a brute I've been idling along like this, talking my head of when you must be freezing and wanting to get a fire."

"But, Mr. Kennedy, I must do something. I must take care of my poor little boy and there is no one to look after us now."

"You are a brave little woman. But I won't have you do this sort of thing. Your family would die of shame."

"Then what will I do?"

"Well, I don't know now but I will think of something."

"Oh, I know you will. You are so smart-Frank."

This conversation takes place when Scarlett fails to borrow money from the imprisoned Rhett Butler. She accidently finds out that her future brother-in-law Frank has saved enough money to resolve the financial crisis of Tara, so she decides that she should have him as her husband to save Tara from being taken away. Therefore, she mentions her underdressing and then changes the topic to the poor psychological state of her current situation and wish for protection from a strong man. Without a word of her economic problems, she tactfully suggests that she is in need of rescue from her present predicament. Just as she plans, Frank fall into her sugarcoated trap and takes the bite willingly. Eventually Scarlett marries Frank and keeps Tara intact. She knows Frank feels the need to rescue a fair lady from her morass and takes good care of her hereafter, so in her flirtation with him, she takes full advantage of it. She is also shrew enough to put it in a way that no man would refuse. This is an indication of her worldly wisdom and sets clues for the wreckage of her second marriage. This flirtation witnesses her bravery to start her own business in a society where "the man was the knight and the woman his virgin, untouched by worldly affairs. whether they were born of a high class or a low one, they were the tender flowers in the world and needed to be taken good care of heart and soul" (Ma, 2014, p. 4). Scarlett challenges these social rules and proves that women can also achieve independence if they are willing to do so. Through this character, the author encourages woman to step out of their traditional rules as housewife and become independent, which is also seen as a sign of inner consciousness.

\subsubsection{Violation of Manner}

Manner Maxim demands that speaker should express himself explicitly, clearly and rationally in order to avert misunderstanding and confusion. However, intentional violations of this maxim can still be rendered and the implicit purpose of the speaker can also be interpreted. Flirtation in Gone with the Wind is one typical example of such violations, for instance:

"Oh, I've been doing nicely, thank you and everything at Tara is fine now. Of course we had a dreadful time right after Sherman went through but, after all, he didn't burn the house and darkies saved most of the livestock by driving it into the swamp. And we cleared a fair crop this last fall, twenty bales. Of course that is practically nothing compared with what Tara can do but we haven't many field hands. Pa says, of course we'll do better next year. But Rhett, it's so dull in the country now. Image there aren't any balls or barbecues and the only thing people talk about is hard times. Goodness, I get sick of it. Finally last week I got too bored to stand it any longer, so Pa said I must take a trip and have a good time. So I came up here to get me some frocks made and I'm going over to Charleston to visit my aunt. It'll be lovely to go to balls again.

"You look beautiful in ball dresses, my dear, and you know it too. Worse luck. I suppose the real reason you are going visiting is that you have run through the country swains and are seeking fresh ones in fields afar."

"oh, well."

"you are a heartless creature, Scarlett, but perhaps that's part of your charm"

"oh, Rehett, how you do run on, teasing a country girl like me. I know mighty well you never gave me a thought 
after you left me that night. You can't tell me you ever thought of me with all those French and English girls around you. But I didn't come all the way out here to hear you talk foolishness about me. I came-I camebecause-"

"Because?"

"Oh, Rhett, I am so terribly distressed about you. So frightened for you. When Will they let you out of that terrible place?"

In this conversation Scarlett gives overloaded and pretentious information about her current state of life. She hesitates and stutters when giving reasons to visit Rhett. This is an act totally contradictory to her lifestyle and characteristics. Therefore there must be something behind. Rhett notices it and blasts his temper, which leads to the failure of her plan to borrow money. In this brief confrontation between Scarlett and Rhett, we can see the pride and vanity of Scarlett. She tries to maintain her reputation even though she is desperately broken. However when Scarlett Faced with such a huge challenge, she did not flinch to the fate, choosing instead to actively fight against it. She always remembered the Pioneering spirit to create a new life with hard work. She stopped being a princess, headed to farm work like a nigger. She commanded the family to work methodically, and she picked cotton and rotten leaves in scorching sun, swearing never again let his family suffer hungry. Later, a Yankee cavalry committed robbery of the estate, she was calm and shot him bravely in order to protect her mother's possessions and hard earned food. Scarlett abandoned the princess inside her when suffering the hardships of life and took responsibility and learned how to find way out in times of hardship, faced reality with toughness and perseverance. ( $\mathrm{Li}, 2014$, p. 76) This conversational implicature displays the two sides of Scarlett and brings her to life. It creates conflicts and promotes the development of the story.

\section{Conclusion}

From the above analysis, we can conclude that the theory of conversational implicature and relevance theory can be applied to the literary criticism in that they have positive effects on the shaping of characteristics, the exposure of social reality and the rendering of conversational motivations. Through a detailed analysis of four classic violations of maxims, the complex character of Scarlett in Gone with the Wind is scrutinized, social causes of such personality are explained and the novelist's intention to promote women consciousness and independence is realized.

This research is conducted under the framework of conversational implicature and relevance theory. Limited to the linguistic analysis of four classic violations of maxims, it is microscopic. Since such detailed research is rare in the pragmatic study of language in literary works, it enlarges the range of the study of flirtations and enriches its contents. Moreover, this kind of research generates new discovery and provides many possibilities in the future research, so we advise a more thorough and effective research in the future.

\section{References}

Cheng, Y. M. (2009). Two points on conversational meaning. Journal of College of Chinese Language and Culture of Jinan University, 3, 53-61.

Claudia, B. (2013). Writing letters in the age of Grice. Philosophy \& Psychology, 1(3), 189-201.

Grice, H. P. (1975). Logic and conversation. In P. Cole \& J. Morgan (Eds.), Syntax and semantics (pp. 41-58). New York: Academic Press.

Jiang, Z. W. (2014). The best marketing is flirting. Sales and Marketing, 10, 14.

Lei, Y. (2012). The expression of conversational meaning in the translation of novel dialogue. Central South University.

Li, P. (2014). Outstanding female characters in Gone with the Wind. The Science Education Article Collects, 32, 76-77.

Ma, C. H., \& Hao, S. J. (2014). Rebellious new woman. Journal of Language and Literature Studies, 8, 85-87.

Mandy, S. (2013). On the conversational basis of some presuppositions. Philosophy \& Psychology, 2(3), 329-348.

Michael, H. (2013). Implicature, inference and cancellability perspectives in pragmatics. Philosophy \& Psychology, 1(1), 133-151.

Nicholas, A. (2014). The non-cooperative basis of implicatures studies in linguistics and philosophy. Philosophy \& Psychology, 2(3), 9-30. 
Philip, H., \& Charles, S. (1979). A problem about conversational implicature. Linguistics and Philosophy, 3(1), 19-25. https:/doi.org/10.1007/BF00578445

Philippe, S. (2012). Maximize presupposition and Grecian reasoning. Natural Language Semantics, 20(4), 391-429. https:/doi.org/10.1007/s11050-012-9085-2

Reynolds, E. (2011). Cues to deception in context: response latency/gaps in Denials and Blame shifting. British Journal of Social Psychology, 50(3), 431-449. https:/doi.org/10.1348/014466610X520104

Siobhan, C. G. (2013). Conversational implicature and philosophy perspectives in pragmatics. Philosophy \& Psychology, 1(3), 153-188.

Soames, S. (2008). Drawing the line between meaning and implicature and relating both to assertion. Philosophy \& Psychology, 42(3), 440-465. https:/doi.org/10.1111/j.1468-0068.2008.00691.x

Tang, X. T (2011). Micro-blog flirt exposed the truth about network anti-corruption. Jiancha Fengyun, 14, 43.

Wayne, A. D. (2013). Irregular negations: Pragmatic explicature theories. Philosophy \& Psychology, 1(3), 303-350.

Wu, C. Q., \& Zhang, Y. L. (2014). Relevance of conversational meaning. Hubei Social Sciences, 6.

Xiao, Z. (2013). Flirting is a hard work. Special Health, 3, 89.

Zhang, Z. (2009). A pragmatic analysis of conversations in Gone with the Wind: A violation of the cooperative principle. Science \& Technology Information, 28, 151-152.

Zhong, F. L. (2014). Studies on verbal irony in Gone with the Wind from the perspective of speech act theory. Journal of Hebei University of Technology (Social Science Edition), 6(3).

\section{Copyrights}

Copyright for this article is retained by the author(s), with first publication rights granted to the journal.

This is an open-access article distributed under the terms and conditions of the Creative Commons Attribution license (http://creativecommons.org/licenses/by/4.0/). 